\title{
Innovative Professional Development and Community Building Activity Program Improves STEM URM Graduate Student Experiences
}

Rosana G. Moreira ${ }^{1 *}$, Karen Butler-Purry², Adrienne Carter-Sowell³, Shannon Walton², Isah V. Juranek², Linda Challoo ${ }^{4}$, Gloria Regisford ${ }^{5}$, Richard Coffin ${ }^{6}$ and Angela Spaulding ${ }^{7}$

\begin{abstract}
Background: Strong consensus exists on the need to expand participation of URM doctoral students in STEM fields, to increase their retention, reduce their average time to degree, and provide these students with the preparation necessary to compete for faculty positions. This paper provides a model for implementing effective strategies to support the success of URM STEM graduate students across a system with various types of institutions. An innovative professional development, participation incentive, and community building program for underrepresented minority (URM) Graduate students in STEM (science, technology, engineering, and mathematics) fields was instrumental in preparing them to secure academic positions, navigating graduate school successfully, and form a support network that helped them excel at the next level. The program provided sustained support and several activities in a collaborative environment for 84 Ph.D. and 84 Master's students, in over 43 graduate programs. Data were collected using evaluation questionnaires containing open-ended responses and responses to specific items sent to the students after each activity, and a survey seeking their feedback on the program.
\end{abstract}

Results: In only 4 years, the program helped 13 students to secure faculty or post-doctoral positions, and improved the opinion of the professoriate career as thirteen students transitioned to the Ph.D. program and are now more interested in applying for faculty positions. The program was successful in developing and sustaining large-scale, distributed, yet interconnected STEM communities among the diverse Alliance system institutions and increased participation (from 58 in 2013 to 98 in 2017), reduced barriers, and promoted the success of URM doctoral students preparing for careers in the professoriate.

Conclusions: We have developed activities that connected students and faculty across institutions, providing multiple paths to the professoriate that align with students' diverse academic career aspirations. This article illustrates that professional development, incentives, and community building interventions are essential in generating URM STEM education transformation.

Keywords: Underrepresented minority, Graduate students, STEM, Professoriate, Professional development, Community building

\footnotetext{
* Correspondence: rmoreira@tamu.edu

'Department of Biological \& Agricultural Engineering, Texas A\&M University,

310 Scoates Hall, College Station, TX 77843, USA

Full list of author information is available at the end of the article
} 


\section{Introduction}

It is clear that the US must remain competitive (Autenrieth, Lewis, \& Butler-Purry, 2017) by continuing investments in science, technology, engineering, and mathematics (STEM) higher education, in particular graduate school, to provide well-trained doctoral degree holders for the US scientific workforce. Doctoral graduates in STEM fields account for a proportionally larger share of the US workforce compared to those in non-STEM fields (National Science Board, 2016). As the US population becomes more diverse, it is critical that STEM as well as non-STEM career pathways become available to all Americans, particularly, underrepresented minorities (URM), defined as American Indians/ Alaska Natives, Blacks/African Americans, Hispanic/ Latinos, Native Hawaiian/Other Pacific Islanders, and other Mixed-Race individuals (Handelsman \& Smith, 2016). Training these individuals would provide the educated workforce necessary to meet the US economic and social demands of the twenty-first century.

In the past 20 years, many federal initiatives were created with a goal of minimizing existing disparity among URM students and whites in higher education STEM fields. Although graduate enrollment for URM students in STEM fields has increased steadily over the last decade, more work needs to be done to increase URM STEM doctorates to equitable rates (Okahana, Klein, Allum, \& Sowell, 2018). Persistent underrepresentation of URMs in the STEM doctoral workforce rightfully causes concern, as it can affect workforce innovation. Therefore, to prepare a future US STEM academic workforce, faculty from universities and colleges must value ethnic diversity, provide supportive participation practices, and reward a multi-cultural learning and research climate (Byars-Winston, 2014).

A study (Sowell, Allum, \& Okahana, 2015) conducted by the Council of Graduate Schools (CGS) provides comprehensive facts on outcomes of URM (AfricanAmerican and Hispanic) students enrolled in STEM doctoral programs at 21 research universities in the USA. Their data shows that the majority $(64 \%)$ of the enrolled URM STEM doctoral students completed their degrees within 10 years and the remaining 36\% withdrew from graduate school. During these 10 years, Hispanic students had higher completion and lower attrition rates than black/African-American students.

A wide range of motives may cause students to withdraw once they have experienced academic life (Sowell et al., 2015): attractive employment opportunities; a poor fit of scientific research with their personal life; change of degree; or the prospect of long, poorly paid graduate school and postdoc years followed by an uncertain career future in a saturated job market. Some URM students may find the culture of graduate school uncongenial, especially if they attend institutions with small URM populations. Sowell et al. (2015) provided examples of institutional actions that may help to mitigate these challenges: early and often interventions; enhanced academic support; program evaluations and interventions; and cultivating a culture of diversity and inclusion. However, more innovative strategies to increase students "motivation to continue-and complete-their studies are still needed".

The main contribution of this paper is to demonstrate that interventions in the areas of professional development together with community building and participation incentives are essential to success of URM STEM graduate students to complete their graduate degrees and secure tenure-track and postdoctoral positions in STEM disciplines. The paper discusses activities in three intervention areas that were implemented as a part of a program facilitated by four institutions (operating in different regional, cultural, geographic, and demographic contexts) in a university system to support URM Ph.D. and Master's STEM students.

\section{Relevant literature review}

Okahana et al. (2018) presented important information on timely completion of STEM doctorates by underrepresented minority students. Their study was based on student level data from the Completion and Attrition in Alliances for Graduate Education and the Professoriate (AGEP) and non-AGEP Institutions project. By using multivariate logistic regression models, they evaluated the effect of different variables on attrition and completion rates, including gender, race, institutions (private versus public, AGEP versus non-AGEP, very high research versus high research), and prior master's degree.

The above mentioned study found that Hispanic/ LatinX and other URM students (American Indian, $\mathrm{Na}$ tive Hawaiian, and Mixed races) were more likely than their Black/African American counterparts to complete their STEM doctorates within 10 years and they were also more likely to earn their STEM doctorates. For Black/African American students, the challenge has more to do with retention than with prolonged completion of their doctoral degrees. The analyses in that study showed that institutional sector and Carnegie Classification matter to the probability of STEM doctoral completion for men, Black/African Americans, and those who started without a prior master's degree. Having a prior master's degree was positively correlated with the chance of earning a doctorate within 10 years among Black/African American students and among URM men in STEM fields. Therefore, efforts such as the NSF AGEP program facilitate doctoral completion of URM doctoral students in STEM fields, and continued investment should focus not only on recruitment of URM students, but also on other aspects of STEM doctoral pipelines such as 
community building. However, building a diverse community should be based on institutional values of diversity and inclusion, which are aligned with institutional missions to support excellence (Butts et al., 2012; Smith \& Calasanti, 2005).

The literature on recruitment and persistence of URM students in STEM graduate programs identified several major challenges (Lovitts, 2008; Ong, Wright, Espinosa, \& Orfield, 2011; Tinto, 2016, 2012). These include social climates and cultural practices in STEM, academic and social integration of students, academic sense of self (selfefficacy), sense of belonging, interpersonal relationships and expectations, attitudes and support of family, mentors, and peers (Gardner, 2008; Lovitts, 2001). Internal assessments in the form of surveys, interviews, focus groups, as well as data on recruitment and retention from Texas A\&M University System URM programs (Bridge To Doctorate-BTD and Louis Stokes Alliances for Minority Participation-LSAMP) provided preliminary data for the development of the TAMUS-AGEP program. In general, the data revealed that URM college students do not pursue doctoral degrees because they do not (1) consider graduate study or academia as a possible goal, (2) understand the process by which a student can pursue such a goal, (3) know the availability of potential career options for those who pursue that path, and (4) think that they could be successful (TAMUS LSAMP Bridges to the Doctorate (HRD-1249272), 2012a, 2012b). Some URM students may also face lack of understanding from family members and the home community, in particular URM students who are first generation college students. An example of a common statement is: "For me, being from a really small town, they won't understand the Ph.D. and what that really means" as quoted in Saenz, Hurtatdo, Barrera, Wolf, and Yeung (2007).

A disconnect in expectations and culture compared to the students' undergraduate program can also present problems when students go from one institution for undergraduate study where, for example, mathematics requirements are less rigorous, to a graduate program at another institution with more rigorous requirements (Goulde, 2005). This issue applies equally to cultural differences; for instance, students may perceive a much more competitive, less nurturing or welcoming atmosphere than what they experienced at their undergraduate institutions. Furthermore, many minority students have financial constraints requiring that they work to support themselves and, sometimes, their families (TAMUS LSAMP Bridges to the Doctorate (HRD-1249272), 2012a). These students may also have dependent children or other family obligations that pose challenges to pursuing full-time graduate study.

Poor student-advisor relationships (lack of trust, interaction, or intellectual support) are a major factor in doctoral student attrition in science and other STEM departments (Goulde, 2005). Furthermore, informal mentoring networks have long been essential to the nurturing of graduate students and development of future faculty (Carter-Sowell, Dickens, Miller, \& Zimmerman, 2016). In situations where minority students are not included in those networks, they experience a distinct disadvantage.

Preliminary assessment (surveys, interviews, focus groups) at our institutions indicated that community building emerged as a key strategy that underpins informal and personal mentoring, enhancing feelings of inclusion, and providing support and encouragement (TAMUS LSAMP, 2012a and 2012b). Multi-level mentoring (where a structured program includes mentoring relationships with peers, faculty, and staff), along with research experiences, and special training related to learning and study strategies, were found to be particularly effective for URM students (Wilson et al., 2012). Mentoring helped URM graduate students negotiate new cultures and expectations they encountered in graduate school, to learn strategies for success, and to avoid feelings of isolation. Moreover, effective mentoring relationships at the doctoral level were characterized by a personal connection between mentor and mentee that went beyond academic and career counseling as presented by Wilson et al. (2012).

TAMUS LSAMP and BTD students who participated in the program evaluation also commented that professional development activities, including monthly workshops and opportunities to present at conferences, proved "extremely helpful" in allowing them to build the skills needed to succeed in graduate studies. Participants mentioned that these components should combine with the student financial support necessary for successful recruitment and retention of URM students. They also stressed that the program should include strong research activities and graduate curricula required for any graduate to compete successfully in the academic job market. Therefore, this article demonstrates the implementation of the activities mentioned above and provides recommendations that may be implemented at other institutions to increase URM STEM graduate students motivation and preparation to compete for faculty positions. The challenge we undertook with this program involved implementing interventions across an Alliance comprised of institutions operating in different regional, cultural, geographic, and demographic contexts.

\section{Methods}

The Texas A\&M System Alliance for Graduate and the Professoriate (TAMUS-AGEP) program, funded by the NSF-AGEP program, aimed at increasing the number of successful URM STEM faculty by measurably increasing the number of STEM doctoral degrees awarded to URM students and the number of URMs transitioning to 
STEM faculty positions (or to competitive postdocs that lead to faculty positions) each year.

The Alliance consisted of five Texas A\&M System Universities: Texas A\&M University, TAMUCS, as the lead institution (a predominant white, public, doctoralhighest research activity university); Prairie View A\&M University (PVAMU) (an HBCU, public, doctoral Universities: Moderate Research Activity university); Texas A\&M University-Corpus Christi, TAMUCC (an HIS, public, doctoral Universities: Moderate Research Activity university); Texas A\&M University-Kingsville, TAMUK (an HIS, public, doctoral Universities: High Research Activity university); and West Texas A\&M University, WTAMU (a predominant white, public, Master's Colleges \& Universities: Larger Programs University).

To improve motivation and enhance the professional skills of URM Doctoral students to become competitive candidates for academia positions, TAMUS-AGEP offered a series of interventions in three areas: (a) professional development, (b) community building, and (c) participation incentives.

Examples of activities included an annual AGEP Conference, a Summer Institute, a Summer National Fellowship and Application Lab, peer-writing workshops, and a series of professional development seminars and workshops to help students plan for successful doctoral and postdoctoral experiences to enable a smooth transition into future academic roles. The program also offered students the opportunity to attend the Southern Regional Education Board (SREB) Teaching \& Mentoring Institute, and Travel Awards and Mini-Grants.

The professional development interventions were designed to develop the following professional and technical skills: (1) Academic development; (2) Leadership and communication development; (3) Instruction and assessment; and (4) Career development. Community-building interventions were intended to increase support and a sense of belonging to URM graduate students at the five participating system institutions. Incentives in the form of travel awards and collaborative mini-grants were created to provide financial support for these experiences to students actively participating in the program. Also, a bonus program encouraged students' participation as they could earn points and receive a participation bonus up to $\$ 2500$ per semester. A few students who were very active in the program were selected to participate as AGEP ambassadors and each received $\$ 500$ for assisting with recruitment and providing leadership in planning and implementation of activities.

Table 1 shows the activities offered by the program in each of the intervention areas. Eighty-seven activities were developed and implemented with 1154 students attending the events. Nineteen students served as program ambassadors from 2013 to 2017. Below follows a description of each main activities offered by the program.
From 2013 to 2017, this AGEP program provided interventions to support the success of 84 Ph.D. and 84 Master's students over 43 STEM graduate programs. Of the total number of students (only US citizens and permanent residents) who participated in the program $(n=$ 168), $55 \%$ of them were female, $63 \%$ were Hispanic Americans, 32\% were African Americans, and 5\% others (Native Hawaiian and Native Alaskan). Figure 1 further illustrates the number of students who participated in the program across these institutions from 2013 to 2017. TAMUCS accounted for $55 \%$ of all students $(n=168)$, while the other institutions added $8-14 \%$, respectively, of the total student participants.

Table 2 lists the total number of URM graduate students who participated in the program per year for each of the institutions in the Alliance. The number of students who participated in the program increased annually for most Institutions. The number of Ph.D. students who participated in the program (data not shown) increased by 2.25 times from 28 in 2013-2014 to 63 in 2016-2017 and the master's students averaged $34 \pm 10$ during the same academic period. New Ph.D. students who joined the program every year averaged $14 \pm 3$ in that period.

\section{Quantitative and qualitative measures}

This research utilized quantitative and qualitative measures to evaluate the participants' perception of how the activities provided professional development skills, community building opportunities/experiences, and incentives.

The data for this paper comprise of three parts: (1) evaluation questionnaires sent to students after each activity, (2) focus group interviews, and a (3) survey administered to all former and current AGEP students seeking their feedback on the program. Data collection efforts were collaborations among TAMUS-AGEP institutions. All the data collected were treated as confidential and were not reported in a way that could be credited to a particular institution or individual. The project includes 168 URM STEM graduate students who participated in the program between September 2013 and August 2017.

\section{Evaluation questionnaires}

After each activity, students were asked to fill out an evaluation questionnaire containing open-ended questions to collect the narrative (qualitative) data coupled with closed-ended questions (quantitative data) to specific items. Figure 2 shows a sample of an evaluation questionnaire.

\section{Focus group interviews}

Focus groups consisted of students in the program and questions typically included the following topics: 
Table 1 How intervention areas and activities are connected in the program

\begin{tabular}{|c|c|c|}
\hline Intervention area $^{a}$ & Activity & Activity connection to Intervention area \\
\hline \multirow[t]{8}{*}{ PD } & Seminars/workshops/informational & Student learns several skills and gains awareness \\
\hline & Travel award & Student develops oral communication skills \\
\hline & SNFAL ${ }^{b}$ & Student develops writing communication skills \\
\hline & Annual TAMUS-AGEP Conference & $\begin{array}{l}\text { Student develops oral communication, leadership, } \\
\text { and career development skills }\end{array}$ \\
\hline & Peer writing groups/support & Student develops writing communication skills \\
\hline & Summer retreats & $\begin{array}{l}\text { Student develops additional skill set, firming } \\
\text { professional development skills }\end{array}$ \\
\hline & Collaborative mini-grants & $\begin{array}{l}\text { Student develops research collaborative skills by } \\
\text { working with faculty from two alliance institutions }\end{array}$ \\
\hline & SREB ${ }^{C}$ participation selection & $\begin{array}{l}\text { Student develops teaching skills at College } \\
\text { and University levels }\end{array}$ \\
\hline \multirow[t]{7}{*}{$C B$} & Welcome back kick-off & $\begin{array}{l}\text { New students share their ideas in a new } \\
\text { community of scholars }\end{array}$ \\
\hline & Summer retreats & Student shares personal issues around a selected theme \\
\hline & Annual TAMUS-AGEP Conference & Students work side-by-side and develop bonds \\
\hline & SNFAL ${ }^{b}$ & Students work side-by-side and develop bonds \\
\hline & Piazza online chats & $\begin{array}{l}\text { Students freely discuss their ideas around } \\
\text { a professional theme }\end{array}$ \\
\hline & End of the year celebration & $\begin{array}{l}\text { Student affirms interactions and feel warm about } \\
\text { the community and themselves }\end{array}$ \\
\hline & SREB ${ }^{C}$ participation selection & Student expands network around their community \\
\hline \multirow[t]{5}{*}{$\mathrm{Pl}$} & Collaborative Mini-grants & $\begin{array}{l}\text { Student receives financial support to } \\
\text { work on their research }\end{array}$ \\
\hline & Participation bonus & $\begin{array}{l}\text { Student receives financial support for active } \\
\text { participation in the program }\end{array}$ \\
\hline & AGEP Ambassadors & $\begin{array}{l}\text { Student receives financial support } \\
\text { and develops leadership skills }\end{array}$ \\
\hline & Travel award & $\begin{array}{l}\text { Student receives financial support to } \\
\text { present her/his research in a conference }\end{array}$ \\
\hline & SREB ${ }^{C}$ participation selection & $\begin{array}{l}\text { Student receives financial support to attend the } \\
\text { Institute of Teaching and Mentoring }\end{array}$ \\
\hline
\end{tabular}

${ }^{a} P D$ professional development, $C B$ community building, $P I$ participation incentives

${ }^{\mathrm{b}}$ SNFL Summer National Fellowship Application Lab

'SREB Southern Regional Education Board

TAMUS-AGEP experiences and personal impacts. The interviews ranged an average length of $20 \mathrm{~min}$.

\section{Participant student survey}

Online survey were administered on 2018 to all former and current AGEP students seeking their feedback on the program (qualitative). The survey included a range of questions regarding students' perceptions of the program, the student experience, and factors that influenced in preparing them to secure academic positions, navigating graduate school successfully, and form a support network that helped them excel at the next level. Responses $(n=38)$ were collected by TAMU-CS and consolidated into one dataset for analyses.

\section{Data analysis}

The qualitative and quantitative data collected were analyzed to address programmatic questions.

Responses from both evaluation questionnaires and surveys were summarized according to three key areas for each activity they attended: professional development, community building, and financial incentives. To understand how useful the interventions in the program were for their career advancement, responses were ranked within these three areas. The quantitative data analysis was based on the responses collected from a Likert 6-point scale multiple-choice questions part of the questionnaire.

Student focus group interview transcripts were independently reviewed and field notes generated, which 


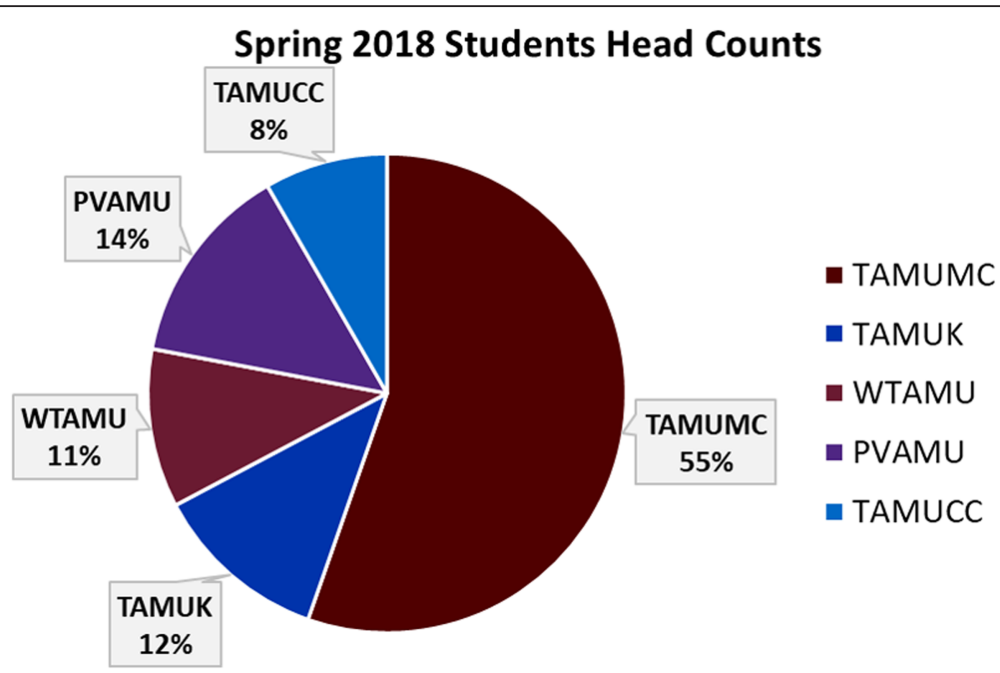

Fig. 1 Number of students participating in the program from 2013-2017 (total \# 168)

summarized reflections on major themes that emerged related to overall program experience, professional development, degree completion, securing Faculty positions, mentoring, networking, and community building.

\section{Results and discussions}

The program was designed to provide a series of activities to help the participants with graduating and succeed in their chosen fields by creating a community of scholars. Because participation was not mandated, not all students attended all the activities for many reasons, including time conflict, topic of interest, location of the activity, etc. We addressed these issues by using different strategies to announce the events (flyers/posters, email listservs, events calendar, social media), providing food, offering activities in the evening, and virtual options. The positive responses of students suggest that means to improve participation should be encouraged by providing, for example, certificates for the professional development activities.

\section{Professional development intervention}

Multiples activities were developed to helped the students to develop their professional skills. Results of the student's responses to questionnaires presented for each professional development activity are shown in Table 3.

\section{The national fellowship application lab}

This activity helped students to develop writing communication skills by preparing and submitting applications to highly competitive and prestigious national fellowships. The labs provided students with information and tips regarding completing a national fellowship application. The labs covered research and/or personal statements, tips for developing a proposal, successful strategies, and proposal-writing process. Networking with their peers was encouraged during the process as they worked in groups and helped each other to achieve the same goals.

The majority $(67 \%)$ of students $(n=13)$ who responded $(n=20)$ noted "very helpful" (Table 3$)$ the information presented at the Summer National Fellowship Lab (SNFL). Twenty-five percent of the students $(n=5)$ indicated the information presented was "helpful" and $8 \%(n=2)$ "not helpful at all."

Although a small number of students responded to the survey, these findings suggest that this activity provided useful information to students and helped them to successfully apply for national fellowships. Five out 20

Table 2 Number of URM STEM graduate students in the program every year per institution

\begin{tabular}{lllllll}
\hline Academic year/institution & TAMUCS & TAMUK & PVAMU & WTAMU & TAMUCC \\
\hline $2013-2014$ & 35 & 7 & 3 & 6 & 0 & Total \\
$2014-2015$ & 52 & 9 & 4 & 4 & 51 & 72 \\
$2015-2016$ & 62 & 13 & 7 & 6 & 6 & 101 \\
$2016-2017$ & 65 & 10 & 7 & 98
\end{tabular}

TASMUCS Texas A\&M University at College Station, TAMUK Texas A\&M University at Kingsville, PVAMU Prairie View A\&M University, WTAMU West Texas A\&M University, TAMUCC Texas A\&M University at Corpus Christi 


\section{TAMUS-AGEP Student Evaluation}

Use a pen or pencil to completely shade the circles corresponding to your responses to the following questions. For open-ended questions, please PRINT or CLEARLY WRITE your responses in the provided areas. Thank you for your help in completing this evaluation form. Your responses will be used in determining the impact of the Conference/Session/Institute/ Workshop and in planning future activities.

\section{Overall Comments about the Fall Annual Conference/Session/Institute/Workshop}

1. What is your overall rating of the Conference/Session/Institute/Workshop?

\begin{tabular}{|c|c|c|c|c|}
\hline Excellent & Very Good & Good & Fair & Poor \\
\hline 0 & 0 & 0 & 0 & 0 \\
\hline
\end{tabular}

2. Indicate the best descriptors of how helpful you believe the following aspects of the Conference/Session/Institute/Workshop will be to you.

\begin{tabular}{|l|c|c|c|c|c|c|}
\hline & $\begin{array}{c}\text { Very } \\
\text { helpful }\end{array}$ & Helpful & $\begin{array}{c}\text { Somewhat } \\
\text { Helpful }\end{array}$ & $\begin{array}{c}\text { Only a } \\
\text { Little } \\
\text { Helpful }\end{array}$ & $\begin{array}{c}\text { Not } \\
\text { Helpful } \\
\text { at All }\end{array}$ & $\begin{array}{c}\text { Not } \\
\text { Sure }\end{array}$ \\
\hline $\begin{array}{l}\text { A. Information presented at the } \\
\text { Conference/Session/Institute/Workshop }\end{array}$ & 0 & 0 & 0 & 0 & 0 & 0 \\
\hline $\begin{array}{l}\text { B. Networking with others at the } \\
\text { Conference/Session/Institute/Workshop }\end{array}$ & 0 & 0 & 0 & 0 & 0 & 0 \\
\hline
\end{tabular}

3. What was most valuable to you about the Conference/Session/Institute/Workshop?

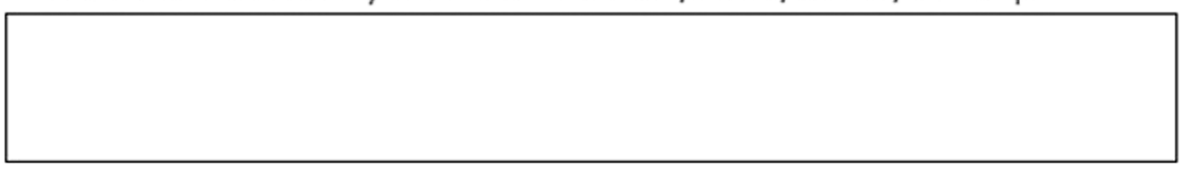

Comments about Session 1- Faculty Roles and Expectations at Different Types of Institutions

4. Did you attend this session?

\begin{tabular}{|c|c|}
\hline Yes & No \\
\hline O & 0 \\
\hline
\end{tabular}

5. What is your overall rating of this session?

\begin{tabular}{|c|c|c|c|c|}
\hline Excellent & Very Good & Good & Fair & Poor \\
\hline 0 & 0 & 0 & 0 & 0 \\
\hline
\end{tabular}

6. How important do you believe sessions like this are for graduate students?

\begin{tabular}{|c|c|c|c|c|}
\hline Very Important & Important & $\begin{array}{c}\text { Somewhat } \\
\text { Important }\end{array}$ & A Little Important & Not Important \\
\hline 0 & 0 & 0 & 0 & 0 \\
\hline
\end{tabular}

Fig. 2 A sample of the questionnaire used to assess student participation on activities

Table 3 How helpful do you believe the following aspects of the event/activity will be for you: information presented during the event/activity?

\begin{tabular}{|c|c|c|c|c|c|c|c|}
\hline Activity & Very & Helpful & Somewhat & Only a little & Not at all & Not sure & \# Responses \\
\hline SNFAL $(n=3)$ & $67 \%$ & $25 \%$ & $0 \%$ & $0 \%$ & $8 \%$ & $0 \%$ & 20 \\
\hline Conference $(n=4)$ & $51 \%$ & $38 \%$ & $7 \%$ & $4 \%$ & $0 \%$ & $0 \%$ & 81 \\
\hline SREB $(n=3)$ & $92 \%$ & $0 \%$ & $8 \%$ & $0 \%$ & $0 \%$ & $0 \%$ & 23 \\
\hline Retreat $(n=3)$ & $76 \%$ & $16 \%$ & $8 \%$ & $0 \%$ & $0 \%$ & $0 \%$ & 52 \\
\hline
\end{tabular}

SNFL Summer National Fellowship Application Lab., SREB Southern Regional Education Board 
students were able to secure funding through fellowship awards, as some of them were selected and/or awarded scholarships/fellowships (one Ford Foundation Dissertation Fellowship, one American Association of University Women (AAUW) Dissertation Fellowship, and three NSF Graduate Research Fellowships).

One student who attended this activity commented that

The program has a plethora of training opportunities. My success in securing external funding is associated with my participation in the summer AGEP National Fellowship Application Lab. During the summer lab sessions, successful grant writers and reviewers exposed me to the best practices on preparing and submitting grant applications. Since my participation in the lab, I secured the following funding: Ford Foundation 2016 Dissertation Fellowship and the American Association of University Women 2016 Dissertation Fellowship.

\section{Annual TAMUS-AGEP conference}

The 2-day conference occurred once per year at different institutions and the majority of the students were supposed to attend the Conference. This activity provided academic support and professional development opportunities to TAMUS AGEP students through workshops, seminars, and presentations. As a community of scholars, students who attended the conferences were supposed to bond with each other, become comfortable to share their personal issues, and encourage each other with positive feedbacks.

From 2103 to 2017, the total attendance of the Conference was 240 (around 33\% were faculty/staff) for the four conferences. Table 3 shows the student evaluations, averaged for the four conferences. When asked how helpful the information presented at this activity was for them, approximately $51 \%$ of the students $(n=41)$ who answered the surveys $(n=81)$ found the AGEP Conferences to be "very helpful," $38 \%(n=31)$ "helpful," $7 \%(n=6)$ "somewhat helpful," and $4 \%(n=3)$ "only little helpful."

These findings suggest that the students appreciated what they learned at all conferences. Some of the students' comments indicate that (1) they liked more engaging and interactive sessions; (2) Q\&A panels proved very instructive to them; (3) PechaKucha $15 \times 20$ presentations helped public speaking while teaching audiences about STEM research; (4) race relations topics should be carefully presented to not look like preaching to the choir; and (5) networking is very important, but they would like to have a more structured session on how to effectively communicate with others outside of their field.

One of the students commented on this activity,
I am already incorporating much [what I learned at the Conference] into the courses I teach as well as mentoring students. I will be honored to attend [the Conference] next year as I gained so much from the experience, it needs to be repeated!! The connection we make, the friends, mentors, collaborators, and all we learn from each other at these conferences makes the road to our PhDs much easier to follow! AGEP participation has grounded me to my university, to my academic aspirations, and fellow graduate students that I would not have if I did not participate in AGEP

\section{Institute on Teaching and Mentoring-Southern Regional Educational Board}

The main goal of this activity, as listed in professional development and community building intervention areas (Table 1), was to develop scholars with needed skills for graduate studies and to prepare them for success as faculty members at colleges and universities. All students who attended the Institute had expressed interest in teaching at the post-secondary level. The numbers of graduate students who qualified to attend the Institute each year ranged from six to 14 . By attending the Conference as a group, it was expected them to expand their network and share deeply with one another and set goals.

Student responses suggest that their persistence in the program might improve when they attend the SREB Teaching and Mentoring Institute workshops as they acquired inspiration and motivation to complete their degrees. Ninety-two percent $(n=21)$ of students who responded to the survey $(n=23)$ found the information presented to be "very helpful" (Table 3).

This activity was very popular among the participants. The students reported gaining inspiration and motivation as the most valuable aspects of this conference. Some of their comments appear below:

The conference was a reminder of what is at and beyond the finish line, what I have to offer my mentors and mentees, and that others have overcome and thrived in situations similar to mine and I can too!

I am re-motivated besides being inspired to complete my PhD even when I have thought of dropping out it is the motivation and inspiration I gain from SREB Institute on Teaching and Mentoring that keeps me in the program. The workshops are great!

We learned from the comments that students value (1) networking and learning the importance of engaging with other scientists; (2) hearing and sharing the 
struggles that help demystify the graduate experience; (3) learning about higher education and the National Center for Faculty Development and Diversity; (4) finding that many other people like them have the same dreams and aspirations; (5) inspirational stories and motivations; (6) career planning activities; and (7) visiting with recruiters.

\section{Summer retreats}

The objective of this activity included providing current students the opportunity to gain additional skill sets based on their current stage in their graduate program (Early, Middle, or Late), strengthening professional development skills, networking with other students and faculty, and participating in community building activities. They learned new tips about work-life balance, stress reduction, and mental health; they discovered new aspects of themselves and others; and developed communication skills.

During the Summer Retreats, 60 students participated in networking activities with peers, staff, and faculty; they acquired new tips surrounding work-life balance, stress reduction, and mental health; they discovered new aspects of themselves and others; and developed communication skills. These activities were designed to strengthen students' sense of belonging and help them to visualize the "finish line." When asked how helpful the information presented at this activity would be for them (Table 3$), 76 \%(n=40)$ of students who responded to this question $(n=52)$ found the information presented to be "very helpful" and 16\% $(n=8)$ "helpful."

Students' comments indicate that they value (1) the opportunity to concentrate on themselves, (2) interaction with their peers, (3) right selection of topics that improve their ability to cope with graduate life in general, and (4) communication. Furthermore, one student said that the summer retreat has proven to be her most valuable experience with the program, while other student commented:

There were so many things that I learned throughout the retreat that I plan on implementing in my life, but my primary focus will be on maintaining the holistic "me" and finding the work/life balance.

\section{TAMUS-AGEP peer writing group and writing support}

The program helped form the Peer Writing Group activity for students. The goal of the Peer Writing Group is to encourage students to write weekly and focus on master's/dissertation proposals, thesis/dissertations, and scholarly publications. Students participating in the Peer Writing Group are paired up and serve as writing accountability partners. This program is aimed at providing support and assistance from their peers. Students were paired up as writing partners for eight pairs from TAMUMC.

Working as a group, students were able to develop their writing skills. The students voiced concerns about having additional writing support and wanted to have a more organized way to receive feedback on what they were working on. To accommodate their needs, the program hired an expert in scientific writing to oversee the Peer Writing Groups.

Some of the testimonials from students who utilized this activity were:

I was overwhelmed by the thought of writing my PhD proposal and felt like my advisor would be upset if he knew that I hadn't been making progress. I took AGEP up on their writing support and scheduled a 1:1 appointment via WebEx. After an hour of meeting, we were able to create a plan so I could finish my proposal on time!

With class and research demands, it is hard for me to devote meaningful time to writing projects, especially when tempted by Netflix. The peer-writing group provides a dedicated space for me to focus on writing without distraction. [The personal writing support] is an invaluable resource for any scientific communications and can guide you through all stages of the writing process. I accomplish much more in a writing session than I do "working from home.

\section{Community building intervention}

The type of program assessed in this paper represents a venue for faculty and students across the Alliance to build cultivating relationships, resulting in students developing a sense of community in the various campuses.

Networking with peers helped them to develop a community of scholars that provided personal support as social interactions. In this section, see a series of activities related to community building. Results of the student's responses to questionnaires presented for each of the community building activity are shown Table 4 .

\section{The National Fellowship Application Lab}

Students were asked to rate how helpful networking with other students at this activity was for them (Table 4), and $59 \%(n=12)$ of students who responded to the survey $(n=20)$ found the networking with others to be "very helpful" to "helpful," $34 \%(n=7)$ between "somewhat helpful" to "only little helpful." 
Table 4 How helpful do you believe the following aspects of the event/activity will be for you: networking with others?

\begin{tabular}{|c|c|c|c|c|c|c|c|}
\hline Activity & Very & Helpful & Somewhat & Only a little & Not at all & Not sure & \# Responses \\
\hline SNFAL $(n=3)$ & $44 \%$ & $15 \%$ & $17 \%$ & $17 \%$ & $0 \%$ & $7 \%$ & 20 \\
\hline Conference $(n=4)$ & $37 \%$ & $31 \%$ & $21 \%$ & $8 \%$ & $2 \%$ & $1 \%$ & 81 \\
\hline $\operatorname{SREB}(n=3)$ & $70 \%$ & $30 \%$ & $0 \%$ & $0 \%$ & $0 \%$ & $0 \%$ & 23 \\
\hline Retreat $(n=3)$ & $72 \%$ & $16 \%$ & $9 \%$ & $3 \%$ & $0 \%$ & $0 \%$ & 52 \\
\hline
\end{tabular}

SNFL Summer National Fellowship Application Lab., SREB Southern Regional Education Board

\section{Annual TAMUS-AGEP conference}

Sixty-eight percent $(n=75)$ of students who responded to the survey $(n=81)$ found the networking with others to be "very helpful" to "helpful," $20 \%(n=17)$ "somewhat helpful," and $10 \%(n=2)$ "only a little" or "not at all helpful" (Table 4).

One of the student commented on this activity,

The connection we make, the friends, mentors, collaborators, and all we learn from each other at these conferences makes the road to our PhDs much easier to follow! AGEP participation has grounded me to my university, to my academic aspirations, and fellow graduate students that I would not have if I did not participate in AGEP

\section{Institute on Teaching and Mentoring-Southern Regional Educational Board}

For the 21 students who participated in this activity, 70\% ( $n=16$ ) found that networking at this activity was "very helpful" and 30\% $(n=7)$ "helpful" (Table 4$)$.

Some of their comments appear below:

...it is the networking, camaraderie, knowledge gained, sharing of experiences, and seeing those individuals who have reached the finish line walk that stage that fires the flames of getting to the finish line myself that is really the most valuable experience of the Conference.

...I met with students from across the country, and several leading mentors in their fields.... I was able to meet with a professor and go over my CV with her. I found this experience extremely rewarding, and am grateful for the opportunity.

\section{Summer retreats}

Networking with other students at this activity (Table 4) was "very helpful" for $72 \%(n=37)$ of the 52 the students who responded to this question.

Three students commented that
The workshops and summer retreats have helped me to network more and discuss my graduate journey with others who could offer support.

During the summer retreat II I learned what kind of person I am, but more importantly I learned how to understand other people, and modify my mannerisms to be a more effective communicator. This experience has impacted me in a tremendously positive way both personally and professionally.

...the summer retreat taught me how to interact better with my PI, which has drastically improved my completion of my PhD.

\section{Online networking platform-Piazza}

Virtual cohorts were created across the TAMUS AGEP alliance institution with Piazza, an online platform, to increase communication among students from different institutions, to encourage a sense of belonging and to create networking opportunities. TAMUS AGEP created several online meeting spaces for students at similar stages in their degree programs.

Although we did not observe large participation during the Piazza chats, the positive aspects of this activity include (1) students facilitated the chats; and (2) small group participation provided richer conversations. Students handled topic selection and led the group chats. One student commented that:

Majority of students $(53 \%, n=23)$ agreed that they felt more prepared to provide mentorship (techniques you learned) because they participated in the Piazza AGEP Café.

\section{Welcome back kick-off facilitate luncheon}

This activity took place in the fall with the objectives of (1) presenting the new programming for the semester, (2) networking and discussions with peers, and (3) developing presentations on a special topic of interest to the students. One student expressed that 
The luncheons [were] helpful as the topics [were] easily digestible in the time the format allowed.

\section{End of year celebration}

This event provides an opportunity for the students to celebrate personal and professional accomplishments. Students shared how the program assisted them throughout their graduate studies. Family members and friends were invited to attend. The end of year celebration helped students to connect and share experiences with friends and family. The program represents a venue for faculty and students across the Alliance to build cultivating relationships, resulting in students developing a sense of community and belonging on the various campuses.

Activities such as luncheons, socials, and retreats really solidified student interaction with and learning from each other. Because of these interactions, small networking groups formed, thus creating a great support system. We found that building an effective community requires an atmosphere of positivity, fun, and ease, and these activities promoted this even further. One student commented

The end of year [celebration] was nice because I was able to interact with the direct of the program 1-on-1.

\section{Participation incentive intervention}

A list of activities that provided monetary incentives to the students are listed below.

\section{TAMUS-AGEP mini-grants and travel awards}

The TAMUS-AGEP mini-grant competition awarded up to $\$ 7,000$ to students to support alliance-wide collaboration activities. The mini-grants provided seed funding to support the development of new collaborative research and/or teaching efforts as well as financial resources to attend conferences to enhance their professional development skills. It must be a collaborative research from at least two Alliance institutions. Travel awards provided financial resources to attend conferences to enhance their professional development skills. Travel expenses were allowed for full-time students, who were active participants in the program and in good academic standing.

Besides providing professional development skills, these activities offer financial incentives to the participants. From 2014 to 2017, 16 students were awarded the mini-grant. The impact of the mini-grants on students appears below:

Monetarily the funding from the AGEP mini grant gave me the data to write two papers that are now the major components of my thesis project. Also the summer retreat taught me how to interact better with my PI, which has drastically improved my completion of my PhD.

My biggest professional development through AGEP has come as a result of being a recipient of the TAMUS AGEP Mini-Grant Award.

My advisor has been very supportive and instrumental in developing the grant supported summer camp for STEM students.

Monetarily the funding from the AGEP mini grant allowed us to pursue our next generation sequencing project looking and gave me the data to write two papers on the microbiome that are now the major components of my thesis project.

During the period of 2015 to 2017, 21 students received a travel award. Three students commented on this program:

...it offered me a travel award for a recognized conference in my field, which was wonderful for networking and sponsored me to participate in the CASE workshop offered by the AAAS which was an amazing exposure to the world of science policy.

... attending this conference was instrumental to the completion of the fundamental goal of my degree plan, that is, to disseminate the results of my doctoral dissertation to was wide audience. The overwhelmingly positive response to my research presentation helped me establish key connections within my academic field.

Not only did I learn about research related to my field and develop and establish new collaborations, but my passion and excitement for [my research area] has been strengthened and invigorated.

\section{TAMUS AGEP ambassador}

One of the highlights of the program is the TAMUS$A G E P$ ambassadors. It provides participation incentives and at the same time students developed leadership and communication skills. Students ambassadors were selected based on their level of participation on all the activities and were responsible for facilitating two Piazza chats per semester; coordinating/facilitating the 
seminar/workshop presented as a luncheon and learning activity or as an evening learning dining; meeting with the Coordinator and Director once a month to discuss future topics for the next semester activities and selecting speakers.

One student commented on her experience

The leadership role [as an AGEP Ambassador] has allowed me to interact with fellow students, faculty, administrators, and staff as an advocate for the program's mission and values. During my on-campus job interviews, I was asked about my AGEP experiences and the overwhelming consensus was that it was obvious that I learned the importance of service and leadership. It was reaffirming to hear first-hand from other universities how well regarded the program is at a national-level.

\section{Summary}

The impact that the above described interventions had on students' skills development while participating in a community scholars is summarized in this section.

Students reported that the professional development activities helped them to become more confident and competitive in the job market. Below are three examples. One former participant who attended 90 activities related to professional development is now a tenure-track assistant professor at a public, doctoral-highest research activity institution. This individual commented on the support received by the program:

"I firmly believe that the Texas Alliance for Graduate Education and the Professoriate (AGEP) was instrumental in preparing me to secure this position, to navigate graduate school successfully, and to form a support network that will help me excel at the next level...each semester my zeal for the program consistently grew as I found new topics that were relevant to my overarching goal of securing a tenuretrack position at a research-intensive institution.

Another student who attended 54 activities and transitioned into a tenure-track assistant professor position at a private, doctoral-highest research activity institution attributed much of the student's success in obtaining a tenure track position to the support provided by the program. The observations about the program are as follows:

There were many occasions throughout graduate school when I was ready to quit. I could do the coursework and research, but I did not see myself as an academic professional. Then one day I decided I was going to make it work and my decision to stay was strongly influenced by joining and participating in AGEP... it provided me with training, skills, and confidence to see myself as being a member of academia, i.e. junior faculty.

Finally, another student who participated in 44 workshops and seminars became a postdoctoral researcher in a public, doctoral-highest research activity institution:

The program has had a huge impact on my progress towards my degree. I have received invaluable professional development skills through opportunities that would not have been available without AGEP. AGEP has also supported me financially, through travel grant, research grants, and stipends (participation bonus).

Analysis of the qualitative data indicates that the professional development program played a role in supporting student success in securing Faculty positions. The activities and supportive environment fostered their professional development away from the laboratory bench. The participants were able to enhance many aspects of their career development beyond their academic/research requirements, including self-care practices, communication skills, and networking skills.

Of the 84 doctoral students, $18 \%(n=15)$ transitioned to post-doctoral, Faculty, or professional career positions. Approximately $40 \%(n=6)$ of the students $(n=$ $15)$ secured tenure-track faculty positions; $47 \%(n=7)$ obtained postdoctoral positions; and $13 \%(n=2)$ chose to continue their studies in professional careers.

In general, participation in the program has affected the future educational and/or career plans of the students. The student participants were pleased with the support and programs related to their educational and career plans. Some students were only interested in a career in industry but after participating in the program they are now interested in a faculty position. Others however were appreciative to know that they have options either in academia or in industry.

Some students commented on the personal impact of the community building intervention:

I can't say enough good things about the program. It has given me motivation at the times when I needed it most. This has come mostly through the personal connections I've made with other people in the program.

The program provide me with a community of scholars. I created a strong bonding and friendship 
with the other participants, that we were able learn about each other, as well as to share our success and struggles during this journey of graduate school.

The most valuable experience has to be the community of individuals I gained who provide advice and a support system as I matriculate through the $\mathrm{PhD}$ process.

When the participants were asked, what was the most valuable program experience and the impact it has had on their educational and career goals, two students stated the following:

There are two prongs, one's been community building. Isolation is a feeling... You live on different sides of the campus and you never see people so it's was fun interacting. We spend time together and get to know each other and that has been really good. But also, you never know what you don't know until someone until someone kind of shoves it in your face, so it's always been really good. The variety of topics that'd been covered and the people that we'd been exposed to, there's been a lot of information so I can't put a price tag on that one.

I think the summer institute when I first met everyone. I thought it was so great to meet so many women in engineering because I come from an area where it's mainly men and when I walked into the room it was majority women and lots of them were engineering and I was just amazed because that was something I hadn't encountered at all.

The participants' indicated that their overall program experience and the extent to which the supported activities have prepared them to accomplish their graduate school tasks were in average "good" to "excellent." The majority of students indicated that after participating in the program they had a better understanding of the various options available including becoming a faculty member and interest in post-doctoral positions. In regarding to the program impact in their career choices, some commented that:

After attending the [Annual Conference] I definitely became more open-minded and knowledgeable in possible post-graduate school careers. Initially I was firm in going to industry after I obtain my Ph.D. but the work in national labs also spurred my interest. Lastly, I realized that many of the responsibilities Ph.D.'s face in their career are similar. For instance, national labs, academia, and even industry are expected to publish and find funding on their own.
The panel of Ph.D.'s at the conference had a major impact on me.

The program has helped me realize that there are more options as far as career choices for my major. Also, I have learned that you should apply for any positions/career paths that interest you even if you feel like you do not have any experience with that specific career and/or company.

Of the students who participated in the program, one doctoral student commented on how programs like ours have helped her succeed in her career even though it took her more than 5 years to graduate:

Despite it taking over 5 years for me to complete my $\mathrm{PhD}$, the program has only provided me with the knowledge that will keep it from taking twice as long. When I have felt that my research was stalled, the program gave me other avenues to succeed in and opportunities to develop professional skills that will ensure my continued success in my program and after it. While my time to degree is certainly longer than I wanted it to be, the program continues to ensure that I do finish and I am successful in my career to follow.

During 2013-2017, 15\% ( $n=13)$ of the master's students $(n=84)$ transitioned to a Ph.D. program. Exposure to Ph.D. peers and participation in activities that promote the professoriate along with academic and social mentorships have motivated some of the master's level students to continue to Ph.D. programs. Two students commented on that:

The program has helped me complete my Master program because of the mentorship that they provided and is one of the main reasons I have continued into my $\mathrm{PhD}$ program and have a better work and life balance.

Well, I'm actually looking at doctoral programs, but I also have and internship with industry. After joining the program, I think it helped me coming out of my shell in this environment. Yea and it pretty much taught me enough professionalism, how to show my character without suppressing my culture. If I list about anything you could possibly need, you can pretty much find it at AGEP.

Another example on how the program influenced completion of many students is illustrated in the statement below: 
Participation in AGEP has truly helped me. It has inspired and motivated me to continue in my degree multiple times.

Evaluation of the program using the data collected suggest that both motivational and professional development activities may improve the chances that graduate students continue their degree and successfully graduate. For example, during the 4 years of TAMUS-AGEP, $18 \%(n=15)$ of the doctoral students who participated in the program $(n=84)$ graduated while only $6 \%(n=5)$ of them dropped out entirely from the University. Of the 84 participant masters students, $45 \%(n=32)$ graduated and $8 \%(n=7)$ dropped out of college. By comparison, the CGS Doctoral initiative on URM attrition and completion study (Sowell et al., 2015) found that $44 \%$ of the STEM students graduated within 7 years, while $36 \%$ of them withdrew from their doctoral programs. The overall median time-to-degree for STEM Doctoral and URM students at TAMU-CS who completed their doctorates in the 2013-2014 to 2016-2017 academic period was 5.99 years (Texas A\&M University - accountability, 2018). Data from other institutions were not considered due to the small population size.

Overall, student participants found the support and programs related to their educational and career plans to be very helpful. At the beginning of this program, some students were only interested in a career in industry, but after participating in the program, they became interested in a faculty position. The program provided support to URM STEM students to remain competitive, and increased the number of URMs admitted to competitive institutions and postdocs. Several participants shared the following comments:

Well, I'm actually looking at doctoral programs, but I also have an internship with industry. After joining the program, I think it helped me coming out of my shell in this environment. Yea and it pretty much taught me enough professionalism, how to show my character without suppressing my culture. If I list about anything you could possibly need, you can pretty much find it at AGEP.

I think the support has been definitely overwhelming. There are many workshops about how to write a resume, to be in a faculty position, and interview. I have taken the advantage and that is what I like about being in the program, there are so many things you can choose to do and it is really up to you what you think you need to be better at.
Future studies of this nature as well as demonstration of impact should pay greater attention to understanding which opportunities URM STEM graduate students invest in as they emerge from isolation, and why students select particular pathways to succeed in finishing their doctoral degrees.

In only 4 years, the program helped 11 students to secure faculty or post-doctoral positions, and improved the opinion of the professoriate career as 13 students transitioned to the Ph.D. program and are now more interested in applying for faculty positions. From the student's comments, 45 percent described that participating in the program influenced their career path by considering the academic track; for example:

The program has encouraged me to pursue the professoriate. Without AGEP, I would most certainly be on a direct path to an industry research job. The AGEP program has given me much insight into the academia as a viable option to pursue.

Feedback from participants indicated that the program should continue to incentivize students to attend professional development activities. Added benefits to students included positive effects on their teaching experience, research activities, successful job searching, and personal and professional achievements that could be linked to their AGEP experiences

A common theme (90\%) from participant responses to the assessment activities was the impact that the professional development seminars and workshops offered by the program had on their career and personal goals. Some comments are given below:

The program gave me the opportunity to participate in professional development workshops that help me get to know myself and what I want to pursue after graduation.

I am a more desirable candidate for any position that I apply for, because of the skills I have gained through the program. For example, the program sent me to a two-week policy workshop in DC. I enjoyed it so much that I applied to a policy fellowship that would start after completion of my PhD. The program highly encourages a path to academia, and so I am also considering post--doc positions so that I will be qualified if I decide to apply for a professor position.

Participants (100\%) indicated that the program should continue sending doctoral students to attend workshops such as the ones offered by the Teaching and Mentoring Institute, at least once a year. It is clear that to better gauge experiences with and benefits of the workshops, participants should provide a reflection describing their 
experiences and the impact on their academic skills and persistence and future career.

The majority of the students $(100 \%$ of those who answered the survey) agreed that the program should continue to provide travel awards to students to present their work or attend scientific conferences. In brief, these opportunities enabled the participants to meet experts in their area of research, present their research results, and attend career fairs.

It is clear from our evaluation that community building (CB) initiatives contributed to students' engagement. While it may appear that there is little empirical quantification of program effects on engagement and impact, qualitative assessment data exist, and clearly show students support of these activities. Students have constantly expressed the importance of networking and that community support makes a great difference in their way to success:

With AGEP I have a network of people who give me a sense of belonging and help me balance my work and relationships.

I cannot say enough good things about the program. It has given me motivation at the times when I needed it most. This has come mostly through the personal connections I have made with other people in the program.

It has helped to feel more confident in my abilities as a student. The community has helped me to reduce my stress and I feel a lot less alone in this process.

In particular, the students liked the Summer Retreats and the Facilitated Luncheons (targeted sessions) and indicated that these activities provide a community of scholars where they can share their success and struggles during this journey of graduate school. Therefore, the prospect of other Institutions of Higher Education with strong commitment to diversity to implement all the activities described in this paper is high.

\section{Conclusions}

The program described in this paper provided sustained support and several activities in a collaborative environment for $84 \mathrm{Ph} . \mathrm{D}$. and 84 Master's students, in over 43 graduate programs. Professional development (PD) interventions assisted URM graduate students in developing the core competencies required of graduate education that can apply to multiple career paths; and participation incentives (PI) and community building (CB) interventions were essential to strengthen URM doctoral student support.
The program was also successful in developing and sustaining large-scale, distributed, yet interconnected STEM communities among the diverse Alliance system institutions and increased enrollment of Ph.D. by $18 \%$ students (from 58 in 2013 to 68 in 2017), reduced barriers, and promoted the success of URM doctoral students preparing for careers in the professoriate. In only 4 years, 13 student's secured faculty or post-doctoral positions; and thirteen students transitioned from master's to doctoral programs

\section{Abbreviations \\ AGEP: Alliances for Graduate Education and the Professoriate; BTD: Bridge to doctorate; CGS: Council of Graduate Schools; CTE: Center for Teaching Excellence; G.R.A.D. Aggies: Graduate Resources and development for Aggies; LSAMP: Louis Stokes Alliances for Minority Participation; PD: Professional development; PVAMU: Prairie View A\&M University; SREB: Southern Regional Education Board; TAMUCC: Texas A\&M University-Corpus Christi; \\ TAMUCS: Texas A\&M University College Station; TAMUK: Texas A\&M University-Kingsville; TAMUS: Texas A\&M System; URM: Underrepresented minority; WTAMU: West Texas A\&M University}

Availability of data and supporting material

All data generated or analyzed during this study are included in this published article.

\section{Authors' contributions}

RGM developed activities, collected and analyzed the data, major contributor in writing the manuscript. KBP provided review on content, data analysis, and on paper preparation. ACS performed retreated activities, provided data collection, analysis, and review of paper preparation. SW developed activities for URM programs and provided data and review of paper preparation. IVJ coordinated the program, developed activities, collected and analyzed data. LC directed the TAMUK activities, provided data collection and analysis. GR direct the PVAMU activities and provided data collection and analysis and review of paper preparation. RC directed the TAMUCC activities, provided data collection, analysis, and review of paper preparation. AS directed the WTAMU activities and provided data collection and analysis. All authors read and approved the manuscript.

\section{Funding}

Funds used in this research was provided by the National Science Foundation (NSF) TAMUS AGEP Transformation Grant: Advancing Interdisciplinary STEM Graduate Education in Energy and Sustainability Disciplines, Award Nos. HRD-1308144, 1308163, 1308149, 1308080, and 1308200 and Texas A\&M University Office of Graduate and Professional Studies.

\section{Ethics approval and consent to participate}

Procedures followed were in approved by and in accordance with the ethical standards of the Institutional Review Board (IRB) at Texas A\&M University Division of research. All participants signed consent forms. IRB ID: IRB2013-0435D—Reference Number: 069613.

\section{Competing interests}

The authors declare that they have no competing interests.

\section{Author details}

${ }^{1}$ Department of Biological \& Agricultural Engineering, Texas A\&M University, 310 Scoates Hall, College Station, TX 77843, USA. ${ }^{2}$ Office of Graduate and Professional Studies, Texas A\&M University, 112 Jack K. Williams Administration Building, College Station, TX 77843, USA. ${ }^{3}$ Department of Psychology \& Brain Sciences, Texas A\&M University, 271 Psychology Bldg, College Station, TX 77843, USA. ${ }^{4}$ Office of Research \& Graduate Studies, Texas A\&M University-Kingsville, 955 N. Univ. Blvd, Kingsville, TX 78363, USA. ${ }^{5}$ Department of Biology, Prairie View A\&M University, 430G E.E. O’Banion Building, Prairie View, Texas 77446, USA. ${ }^{6}$ Department of Physical \& Environmental Sciences, Texas A\&M University-Corpus Christi, 6300 Ocean 
Dr, Corpus Christi, TX 78412, USA. ${ }^{7}$ The Graduate School, Killgore Research Center, Room 104A, West Texas A\&M University, 25th St, Canyon, TX 79015, USA

Received: 23 August 2018 Accepted: 27 August 2019

Published online: 07 October 2019

\section{References}

Autenrieth, R. L., Lewis, C. W., \& Butler-Purry, K. (2017). Long-term impact of the enrichment experiences in engineering $\left(E^{3}\right)$ summer teacher program. Journal of STEM Education, 19(4), 19-29.

Butts, G. C., Hurd, Y., Palermo, A.-D. S., Delbrune, D., Saran, S., Zony, C., \& Krulwich, T. (2012). Role of institutional climate in fostering diversity in biomedical research workforce: a case study. Mt Sinai Journal of Medicine, 79(4), 498-511.

Byars-Winston, A. (2014). Toward a framework for multicultural STEM-focused career interventions. The Career Development Quarterly, 62, 340-357.

Carter-Sowell, A. R., Dickens, D. D., Miller, G., \& Zimmerman, C. A. (2016). Present but not accounted for: examining how marginalized intersectional identities create a double bind for women of color in the academy. In J. Ballenger, B. Polnick, \& B. Irby (Eds.), Women of Color in STEM: Navigating the Workforce in Research on Women and Education series (pp. 181-200). Charlotte: Information Age Publishing.

Gardner, S. K. (2008). What's too much and what's too little?: the process of becoming an independent researcher in doctoral education. Journal of Higher Education, 79, 326-350.

Goulde, C. M. (2005). The role of the department and discipline in doctoral student attrition: Lessons from four departments. The Journal of Higher Education, 76(6), 669-700

Handelsman, J., \& Smith, M. (2016). STEM for all. Washington, DC: The Obama Administration White House https://obamawhitehouse.archives.gov/blog/2 016/02/11/stem-all. Assessed 05 Apr 2018.

Lovitts, B. E. (2001). Leaving the ivory tower: the causes and consequences of departure from doctoral study. New York: Rowman and Littlefield.

Lovitts, B. E. (2008). The transition to independent research: who makes it, who doesn't, and why. The Journal of Higher Education, 79(3), 296-325.

National Science Board. (2016). Science and engineering indicators 2016, NSB-20161. Arlington: National Science Foundation.

Okahana, H., Klein, C., Allum, J., \& Sowell, R. (2018). STEM doctoral completion of underrepresented minority students: challenges and opportunities for improving participation in the doctoral workforce. Innovative Higher Education., 43(4), 237-255.

Ong, M., Wright, C., Espinosa, L., \& Orfield, G. (2011). Inside the double bind: a synthesis of empirical research on undergraduate and graduate women of color in science, technology, engineering, and mathematics. Harvard Educational Review., 81(2), 172.

Saenz, V. B., Hurtatdo, S., Barrera, D., Wolf, D., \& Yeung, F. (2007). First in my family: a profile of first-genetation college students at four-year institutions since 1971. Los Angeles: Higher Eduaction Research Institute, UCLA.

Smith, J. W., \& Calasanti, T. (2005). The influences of gender, race and ethnicity on workplace experiences of institutional and social isolation: an exploratory study of university faculty. Sociological Spectrum, 25, 307-334.

Sowell, R., Allum, J., \& Okahana, H. (2015). Doctoral initiative on minority attrition and completion. Washington, DC: Council of Graduate Schools.

TAMUS LSAMP Bridges to the Doctorate (HRD-1249272). (2012a). Interview Report.

TAMUS LSAMP Bridges to the Doctorate (HRD-1249272). (2012b). PVAMU Focus Group Report.

Texas A\&M University—accountability. (2018). https://accountability.tamu.edu/AllMetrics/Mixed-Metrics/Student-Demographics. Accessed 05 Apr 2018.

Tinto, V. (2012). Completing college. Rethinking institutional action (p. 283). The University of Chicago Press.

Tinto, V. (2016). From retention to persistence. Inside higher Ed. Opinion. https:// www.insidehighered.com/views/2016/09/26/how-improve-studentpersistence-and-completion-essay

Wilson, Z. S., Holmes, L., DeGravelles, K., Sylvain, M., Batiste, L., Johson, M., McGuire, S. Y., Pang, S. S., \& Warner, I. M. (2012). Hierarchical mentoring: a transformative strategy for improving diversity and retention in undergraduate disciplines. Journal of Science Education and Technology, 21, 148-156.

\section{Publisher's Note}

Springer Nature remains neutral with regard to jurisdictional claims in published maps and institutional affiliations.

\section{Submit your manuscript to a SpringerOpen ${ }^{\circ}$ journal and benefit from:}

- Convenient online submission

- Rigorous peer review

- Open access: articles freely available online

- High visibility within the field

- Retaining the copyright to your article

Submit your next manuscript at $\boldsymbol{\nabla}$ springeropen.com 